\title{
Analytical Modeling of Variable Density Multilayer Insulation for Cryogenic Storage
}

\author{
A. HEDAYAT \\ Sverdrup Technology, Inc., MSFC Group \\ Huntsville, AL \\ L.J. HASTINGS and T. BROWN \\ NASA, Marshall Space Flight Center \\ Huntsville, AL
}

\begin{abstract}
A unique foam/Multilayer Insulation (MLI) combination concept for orbital cryogenic storage was experimentally evaluated at NASA Marshall Space Flight Center (MSFC) using the Multipurpose Hydrogen Test Bed (MHTB). The MLI was designed for an on-orbit storage period of 45 days and included several unique features such as: a variable layer density and larger but fewer perforations for venting during ascent to orbit. Test results with liquid hydrogen indicated that the MLI weight or heat leak is reduced by about half in comparison with standard MLI. The focus of this paper is on analytical modeling of the Variable Density MLI (VD-MLI) on-orbit performance (i.e. vacuum/low pressure environment). The foam/VD-MLI combination model is considered to have five segments. The first segment represents the optional foam layer. The second, third, and fourth segments represent three MLI segments with different layer densities. The last segment is considered to be a shroud that surrounds the last MLI layer. Two approaches are considered. In the first approach, the variable density MLI is modeled layer by layer while in the second approach, a semi-empirical model is applied. Both models account for thermal radiation between shields, gas conduction, and solid conduction through the layer separator materials.
\end{abstract}

\section{INTRODUCTION}

Future space programs and missions require efficient delivery of large payloads over great distances, necessitating the use of high-energy cryogenic upper stages. Therefore, Cryogenic Fluid Management (CFM), including efficient and reliable insulation materials, is a crucial part of future space exploration. Insulation is a key element in long duration missions requiring cryogenic storage since relatively small heat fluxes can result in significant boil off losses, increased tank pressure, and increased liquid saturation conditions.

Multilayer insulations for cryogenic storage are designed for high vacuum conditions and typically consist of many radiation shields separated with a low conductivity spacer material between the hot and cold boundaries. The radiation shielding normally consists of a thin plastic

film coated on one or both sides with a thin layer of high reflectance metal, usually aluminum or gold. A detailed review of MLI is provided by Tein and Cunnigton ${ }^{1}$. Multilayer Insulation systems are often comprised of multiple Double Aluminized Mylar (DAM) radiation shields with 
Dacron net spacer material between shields. While radiation generally dominates heat transfer, solid conduction through the spacer material becomes an issue at low temperatures such as those experienced by the inner MLI layers on a cryogenic fluid tank. To optimize the MLI for a cryogenic application, the colder inner layers can be separated by greater distance than the warm outer layers where radiation dominates heat transfer. This type of MLI, referred to as Variable Density MLI (VD-MLI) because the layer spacing varies across the MLI cross-section, reduces both insulation mass and thermal heat leak. The spacing geometry in a VD-MLI system can be controlled by the addition of bumper strips constructed by folding Dacron netting. The bumper strip thickness can be easily adjusted by varying the number of folds.

MLI systems are suitable for low-pressure environments, whereas, at higher pressures, simple foam insulation easily outperforms MLI. Thus, hybrid insulation concepts, combining foam insulation for atmospheric heat transfer protection and MLI for optimum resistance during orbital/space flight, have often been proposed in earth-based upper-stage studies.

\section{HYBRID INSULATION TESTING}

Since a hybrid insulation designed for several weeks of orbital cryogenic storage had not been previously tested, a hybrid concept using a VD-MLI was experimentally evaluated by Hastings and Martin ${ }^{2}$ in 1996 using a large scale test article ( 3 meter diameter by 3 meter long with a volume of 18 cubic meters) termed the Multipurpose Hydrogen Test Bed (MHTB). In addition to protecting against ground-hold/ascent-flight environments, the spray-on foam insulation (SOFI) substrate successfully allowed the use of a prelaunch dry nitrogen purge as opposed to a helium purge subsystem normally required with MLI in liquid hydrogen applications. Due to a reduced ground-hold heat leak, the foam also enabled a liquid hydrogen density degradation of three percent or less as compared to thirteen percent with an "MLI only" system, as reported by Kramer et $\mathrm{al}^{3}$. The VD-MLI (45 layers of Double Aluminized Mylar (DAM) with Dacron net spacers) incorporated several innovative features and was designed for an on-orbit storage period of 45 days. In addition to the variable layer density, larger but fewer DAM perforations were implemented for venting during ascent to orbit, thus, reducing radiation losses. Additionally, the roll wrap installation process provided a robust MLI and reduces both assembly man-hours and seam heat leak. A detailed description of the MHTB and its VD-MLI was provided by Hastings and Martin ${ }^{2}$.

The MHTB simulated orbit-hold test periods produced heat leaks of 0.085 and $0.22 \mathrm{Watts} / \mathrm{m}^{2}$ with warm boundary temperatures of $164 \mathrm{~K}$ and $305 \mathrm{~K}$, respectively. When compared to the best previously measured performance with a traditional MLI system, as reported by Fredrickson ${ }^{4}$, a $41 \%$ heat leak reduction was achieved with 25 fewer layers. Additionally, when compared with calculated performance of a constant-density MLI (with standard perforations) using the industry standard "Lockheed Equation"5 and holding the blanket weight constant, the VD-MLI heat leak was less than half that of the standard blanket at the higher boundary temperature. Similarly, analysis suggested that standard blankets of equal performance, weigh 74 percent more than the VD-MLI. System performance does; however, tend to converge at the lower boundary temperature of $164 \mathrm{~K}$ due to the decreased significance of radiation exchange between layers. 
The primary purpose this paper is to facilitate extension of the "MHTB type insulation" concept
to other applications by describing analytical modeling techniques developed for a VD-MLI
combined with the larger and fewer vent holes and an optional SOFI substrate.

\section{MODELING OVERVIEW}

To evaluate VD-MLI performance, two analytical models are presented. The Layer-by-Layer model is based on a methodology developed by McIntosh ${ }^{6}$, and the other model is a modification of the Lockheed method ${ }^{5}$. The analytical modeling of the insulation during orbital coast periods is discussed in subsequent sections.

\section{Layer-by-Layer Model}

The Layer-by-Layer model, based on the work of McIntosh ${ }^{6}$ on a separated model equation to simulate MLI performance, accounts for three modes of heat transfer: thermal radiation between shields, gas conduction, and solid conduction through the separator materials. The total heat flux through the each layer of MLI is,

$$
\mathrm{q}_{\text {total }}=\mathrm{q}_{\text {radiation }}+\mathrm{q}_{\mathrm{gas}} \text { conduction }+\mathrm{q}_{\text {solid conduction }}
$$

The radiation heat transfer is,

$$
\mathrm{q}_{\text {radiation }}=\sigma\left(\mathrm{T}_{\mathrm{H}}^{4}-\mathrm{T}_{\mathrm{C}}{ }^{4}\right) /\left(1 / \varepsilon_{\mathrm{H}}+1 / \varepsilon_{\mathrm{C}}-1\right)
$$

$\sigma$ represents Stephan-Boltzmann constant $\left(5.675 \mathrm{E}-8 \mathrm{~W} / \mathrm{m}^{2}-\mathrm{K}^{4}\right), \mathrm{T}_{\mathrm{H}}$, and $\mathrm{T}_{\mathrm{C}}$ represent warm and cold layer surface temperatures $(\mathrm{K})$, and $\varepsilon_{\mathrm{H}}$ and $\varepsilon_{\mathrm{C}}$ are the emissivities of the warm and cold layer surfaces, respectively.

For the low pressure/vacuum environment, the space between the shields is considered to be in free-molecule regime, therefore, the gas conduction equation formulated by Corruccini ${ }^{7}$ is applied,

where

$$
\mathrm{q}_{\text {gas conduction }}=\mathrm{C}_{1} \mathrm{P} \alpha\left(\mathrm{T}_{\mathrm{w}}-\mathrm{T}_{\mathrm{C}}\right)
$$

$\mathrm{k}_{\mathrm{g}}=\mathrm{C}_{1} \mathrm{P} \alpha=$ gas conductivity, $\mathrm{W} / \mathrm{m}^{2}-\mathrm{K}$

$\mathrm{T}=$ temperature of vacuum gage, normally $300 \mathrm{~K}$

$\mathrm{C}_{1}=[(\gamma+1) /(\gamma-1)][\mathrm{R} / 8 \pi \mathrm{M} \mathrm{T}]^{1 / 2}$

$\mathrm{R}=$ gas constant, $8.314 \mathrm{~kJ} / \mathrm{mol}-\mathrm{K}$

For air, $\mathrm{C}_{1}=1.1666$ and for helium 2.0998 .

Conduction through the solid is expressed as,

$$
\mathrm{q}_{\text {solid conduction }}=\mathrm{K}_{\mathrm{s}}\left(\mathrm{T}_{\mathrm{H}}-\mathrm{T}_{\mathrm{C}}\right)
$$

Where, $\mathrm{K}_{\mathrm{s}}=\mathrm{C}_{2} \mathrm{f} \mathrm{k} / \mathrm{DX}$, DX represents actual thickness of separator between reflectors, $\mathrm{k}$ is separator material conductivity $(\mathrm{W} / \mathrm{m}-\mathrm{K}), \mathrm{C}_{2}$ is an empirical, and $\mathrm{f}$ represents separator density /solid material density. 
Curve fit equation for Dacron conductivity as a function of temperature, $\mathrm{T}$, is provided as the following :

$$
\begin{aligned}
& \mathrm{k}=0.017+7 \mathrm{E}-6^{*}(800-\mathrm{T})+0.0228 \ln (\mathrm{T}) \\
& \mathrm{C}_{2}=0.008
\end{aligned}
$$

\section{Modified Lockheed Model}

The Lockheed model ${ }^{5}$ also allows three heat transfer mechanisms, namely: conduction through solid, conduction through gas, and radiation between shields. The semi-empirical expression for total heat flux through a standard MLI segment (i.e. constant layer density) as follows:

$$
\begin{gathered}
\mathrm{q}_{\text {total }}=\mathrm{q}_{\text {solid conduction }}+\mathrm{q}_{\text {radiation }}+\mathrm{q}_{\mathrm{gas} \text { conduction }} \\
\mathrm{q}_{\text {total }}=\mathrm{A}\left(\mathrm{N}^{*}\right)^{\mathrm{n}} \mathrm{T}_{\mathrm{m}}\left(\mathrm{T}_{\mathrm{H}}-\mathrm{T}_{\mathrm{C}}\right) / \mathrm{N}_{\mathrm{s}}+\mathrm{B} \varepsilon \sigma\left(\mathrm{T}_{\mathrm{H}}{ }^{4.67}-\mathrm{T}_{\mathrm{C}}{ }^{4.67}\right) / \mathrm{N}_{\mathrm{s}} \\
+\mathrm{C} \mathrm{P}^{*}(\mathrm{x}, \mathrm{T})\left(\mathrm{T}_{\mathrm{H}}{ }^{(\mathrm{m}+1)}-\mathrm{T}_{\mathrm{C}}{ }^{(\mathrm{m}+1)} / \mathrm{N}_{\mathrm{s}}\right.
\end{gathered}
$$

where $P^{*}(x, T)$ is the pressure within the insulation as a function of position and local temperature, and coefficients $\mathrm{A}, \mathrm{B}$, and $\mathrm{C}$, as well as the exponents $\mathrm{m}$ and $\mathrm{n}$, are derived from the particular insulation system and interstitial gas.

For perforated aluminized shields, nitrogen gas (at low pressure/vacuum environment), and Tissuglas spacer material, the suggested Lockheed Equation for the total heat transfer becomes the following:

$$
\begin{aligned}
\mathrm{q}_{\text {total }}= & 7.30 \times 10^{-8}\left(\mathrm{~N}^{*}\right)^{2.63} \mathrm{~T}_{\mathrm{m}}\left(\mathrm{T}_{\mathrm{H}}-\mathrm{T}_{\mathrm{C}}\right) / \mathrm{N}_{\mathrm{s}}+7.07 \times 10^{-10} \varepsilon\left(\mathrm{T}_{\mathrm{H}}{ }^{4.67}-\mathrm{T}_{\mathrm{C}}{ }^{4.67}\right) / \mathrm{N}_{\mathrm{s}} \\
& +1.46 \times 10^{4} \mathrm{P}^{*}\left(\mathrm{~T}_{\mathrm{H}}{ }^{0.52}-\mathrm{T}_{\mathrm{C}}{ }^{0.52}\right) / \mathrm{N}_{\mathrm{s}}
\end{aligned}
$$

Where, $\mathrm{P}^{*}$ is in torr, $\mathrm{q}_{\text {total }}$ in $\mathrm{w} / \mathrm{m}^{2}, \mathrm{TH}, \mathrm{TC}$ in degree $\mathrm{K}, \mathrm{N}^{*}$ layer density (\# layers $/ \mathrm{cm}$ ), and $\mathrm{N}_{\mathrm{s}}$ represents number of shields.

In the original Lockheed Equation ${ }^{5}$, the spacer material and the shield hole sizes were different than those of the MHTB test article; therefore, the empirical parameters A and B were adjusted for the MHTB insulation. The coefficient A influences the conduction through the spacer. The spacer material in the original Lockheed equation was Tissuglas, while in the test article, Dacron spacer material was used. To modify the solid conduction term, the Dacron conductivity function provided by McIntosh is incorporated into the conduction term. The radiation coefficient $B$ in the Lockheed equation accounts for radiative transfer between the shields and was provided for perforated shields of $0.119 \mathrm{~cm}(0.047$ inches $)$ hole diameter and a fractional open area (holes area/shield area) of 0.01 . To adjust the value of $B$ for the perforated shields used in the MHTB MLI [hole diameter of $1.27 \mathrm{~cm}$ (0.5 inches) and fractional open area of 0.02 ], reference 8 was used. Reference 8 provides empirical radiative heat flux curves as functions of hole size and open area ratio. These data were used to determine a correction factor for the "B" coefficient [Qrad ${ }_{\text {Lockheed configuration }} / \mathrm{Qrad}_{\mathrm{MHTB}}$ configuration], accounting for the hole size and open area ratio of the MHTB VD-MLI system. The adjusted value of B was found to be 4.944E-10. The 
coefficient $\mathrm{C}$ represents the convective effects of the interstitial gas, nitrogen, and no adjustment was required. Therefore, the Modified Lockheed equation becomes the following:

$$
\begin{aligned}
\mathrm{q}_{\text {total }}= & 2.4 \times 10^{-4} *[0.017+7 \mathrm{E}-6(800-\mathrm{T})+0.0228 \ln (\mathrm{T})]^{*}\left(\mathrm{~N}^{*}\right)^{2.63}\left(\mathrm{~T}_{\mathrm{H}}-\mathrm{T}_{\mathrm{C}}\right) / \mathrm{N}_{\mathrm{s}} \\
& +4.944 \times 10^{-10} \varepsilon\left(\mathrm{T}_{\mathrm{H}}{ }^{4.67}-\mathrm{T}_{\mathrm{C}}{ }^{4.67}\right) / \mathrm{N}_{\mathrm{s}}+1.46 \times 10^{4} \mathrm{P}\left(\mathrm{T}_{\mathrm{H}}{ }^{0.52}-\mathrm{T}_{\mathrm{C}}{ }^{0.52}\right) / \mathrm{N}_{\mathrm{s}}
\end{aligned}
$$

\section{ANALYTICAL RESULTS AND DISCUSSIONS}

Figure 1 depicts the MHTB tank schematic with a foam/VD-MLI combination divided into five different segments. $T_{C}$ and $T_{H}$ represent tank wall temperature and shroud temperature, respectively. The heat flux through each segment and temperature of interface of adjacent segments are represented by the corresponding $q$ and $T$, respectively. The first segment is the foam. The second, third and fourth segments represent the three segments of MLI with different layer density and number of shields. The layer density $\mathrm{N}^{*}$, and number of shields for MLI segments 1 thru 3 are 8,12, and 16 layers $/ \mathrm{cm}$, and 10,15,20 shields, respectively. Finally, the last segment is considered to be the shroud with an emissivity of 0.04 . For the steady state conditions, the heat flux through the MLI system is modeled using the modified Lockheed equation. The model was comprised of the described segments. Therefore, the heat transfer model consisted of conduction through the foam, 3 segments of MLI using the Lockheed equation for each segment, and radiation exchange between the shroud and the last MLI shield. The Cold Temperature Boundary condition at the interior of the foam and hot temperature at the exterior of the shroud describe the cryogenic liquid and the environment, respectively. Experimental data contained a Cold Temperature Boundary of $20 \mathrm{~K}$ while the Hot Boundary Temperatures are $164 \mathrm{~K}$, and $305 \mathrm{~K}$. At steady state conditions, the heat flux relation can be written as

$$
\mathrm{q}_{\mathrm{foam}}=\mathrm{q}_{\mathrm{seg} 1}=\mathrm{q}_{\mathrm{seg} 2}=\mathrm{q}_{\mathrm{seg} 3}=\mathrm{q}_{\text {shroud }}
$$

The qs and, $T_{1}, T_{2}, T_{3}$, and $T_{4}$ are unknowns. Using equation (10), a system of four equations with four unknowns can be developed. Because of the radiation terms, this system of equations is nonlinear and is solved iteratively. First, for prescribed Cold and Hot Boundary temperatures, initial MLI segment interface temperatures are assigned. Then, the heat rate through each segment is calculated. Using the heat rate and guessed temperature, the resistance of each segment is computed. Then, new temperatures are computed using the new heat rate and resistance of each segment. The process is repeated until the solution converges. The convergence of the solutions implies that the total heat transfer rate through each segment is the same and the temperature of each MLI segment interface for two consecutive iteration steps becomes equal within an allowable difference. In the Layer-by-Layer approach, the foam, each shield layer, and the shroud are considered to be separate nodes. Therefore, the foam/MLI system model is comprised of 47 nodes. The steady state heat flux through MLI was calculated using the McIntosh model and applying a computational procedure similar to that of the Lockheed model described earlier. Based on the described methods, two spreadsheet models were developed. These spreadsheets could be useful tools in design optimization and performance evaluation of MLI systems. 
Comparison between the heat flux values predicted by both models and those of the measured data is depicted in Figure 2. Compared with the MHTB test data, for higher Hot Boundary Temperature, the heat flux values predicted by the Layer-by-layer model and modified Lockheed equation are within $5 \%$ and $8 \%$, respectively. While for the lower Hot Boundary Temperature, the predictions are within $34 \%$ and $30 \%$ for the Layer-by-Layer and Modified Lockheed, respectively. It is believed that the lack of correlation at the lower temperature boundary condition is because a "lower than actual" effective thermal conductivity is computed by the models. Apparently, the relative errors in the empirical computations of radiation and conduction effects compensate such that the correlation with the test data is relatively good at higher boundary temperatures; whereas, the conductivity term dominates at the lower temperatures and the deviation is manifested.

VD-MLI application examples on a Centaur G Prime upper stage liquid hydrogen (LH2) tank with a 0.25 mil DAM are tabulated in Table 1 for a 45 day mission. With a liquid hydrogen tank surface area of $81.6 \mathrm{~m}^{2}$, the weight difference between the VD-MLI and "standard Lockheed model" MLI blanket would be $43 \mathrm{~kg}$ (standard weighs $75 \%$ more) if the boiloff is held constant. Conversely, if the blanket weights are held constant, the boiloff is $159 \mathrm{~kg}$ and $382 \mathrm{~kg}$ with the VD-MLI and standard MLI, respectively.

The two analytical modeling techniques are also compared through application to three hypothetical SOFI/VD-MLI systems with blanket thicknesses different than those of the MHTB test article. The VD-MLI systems simulated are 30, 60, and 75 layers. Each system is considered to have physical and thermal properties similar to those of the MHTB 45 layer SOFI/VD-MLI system. Figures 3, 4, and 5 illustrate the predicted heat flux for the VD-MLI systems of 30, 60, and 75 layers, respectively. The predicted heat flux values at the highest Hot Boundary Temperature are within $6 \%$. As the Hot Boundary Temperature is lowered, heat flux predicted by both models converge to similar value. The results for the SOFI/VD-MLI system indicate that both the Layer-by-Layer and Modified Lockheed models simulations are consistently within $6 \%$.

\section{CONCLUSIONS}

In conclusion, either the Layer-by-Layer or the Modified Lockheed Equation spreadsheet model can be utilized in multiple applications to predict the performance of the "MHTB type" SOFI/VDMLI combination or the VD-MLI alone. In the development of the analytical model for the VDMLI, it was observed that larger, more widely spaced ventilation holes provided a significant radiation blockage advantage as compared with the standard, closely spaced smaller holes. The variable density contributed to a weight reduction or performance increase due to reduced conduction with fewer layers to perform the same task. The lack of seams, butt joints, and structural support pins no doubt contributed to the measured MHTB performance improvement as well. Application of the "MHTB type", or VD-MLI, to other liquid hydrogen storage systems can result in insulation weight and/or boiloff savings of $43 \%$ and $58 \%$ respectively. The foam insulation not only enabled the elimination of a helium purge system, but also reduced the ground hold heat leak sufficiently to improve the effective density of the loaded LH2 as compared with an "MLI" only concept. 


\section{REFERENCES}

1. Tein, C. L., and Cunnigton, G. R., "Cryogenic Insulation Heat Transfer," Advances in Heat Transfer, pp. 349-417, Volume 9, 1973.

2. Hastings, L. J. and Martin, J. J., "Experimental Testing of a Foam/Multilayer Insulation (FMLI) Thermal Control System (TCS) for use on a Cryogenic Upper stage," Space Technology Applications International Forum, $1^{\text {st }}$ Conference on Orbital Vehicles, Albuquerque, NM, January 25-28, 1998.

3. Kramer, E. W., Brogren, E.W., and Seigel, B.L., "Evaluation of Propellant Tank Insulation Concepts for Low-Thrust Chemical Propulsion Systems", Final Report, Boeing Aerospace Co., Contract NAS3-2284, March 1984.

4. Fredrickson, G. O., "Investigation of High-Performance Insulation Application Problems, Final Report". Contract NAS8-21400, McDonnell Douglas Astronautics Co Report MDC G4722, August 1973.

5. Keller, C. W., Cunnington, G. R., and Glassford, A. P.:"Thermal Performance of Multi-Layer Insulations, Final Report, Contract NAS3-14377, Lockheed Missiles \& Space Company, 1974.

6. McIntosh, G. E., "Layer by layer MLI calculation Using a Separated Mode Equation," Cryogenic technical Services Inc., Boulder, CO.

7. Corruccini, R. J., "Gaseous Heat Conduction at Low Pressures and temperatures," Vacuum, VIII, pp. 19-29, 1959.

8. "Thermal Insulation Systems A survey," Chapter 4, NASA Report SP-5027, August 1967.

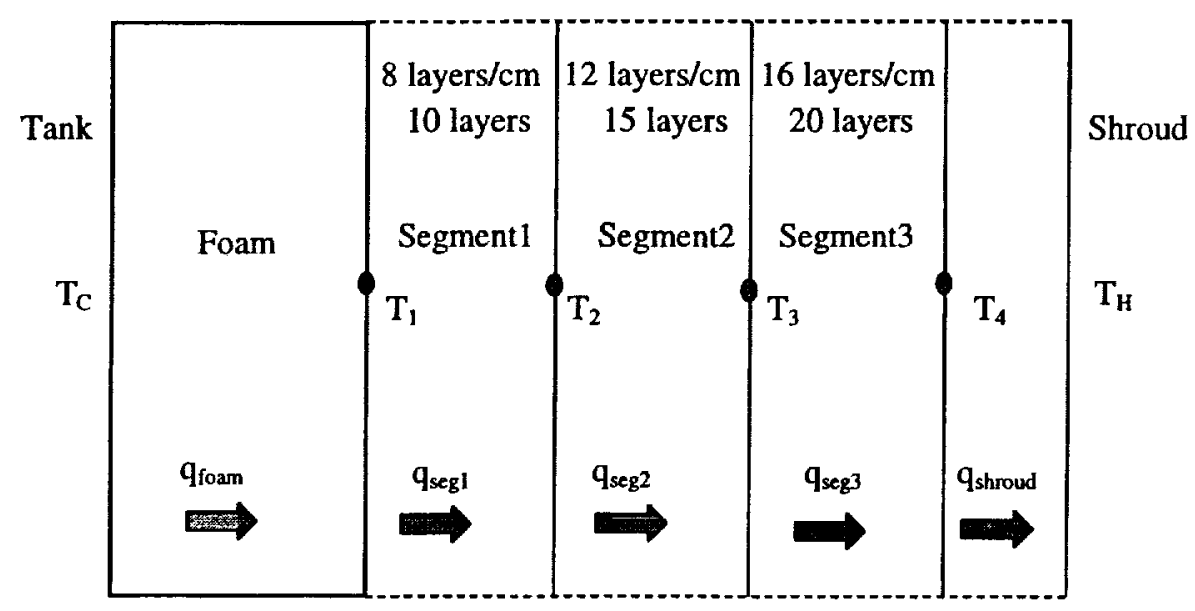

Figure 1. Foam/VD-MLI Sysems Schematics. 


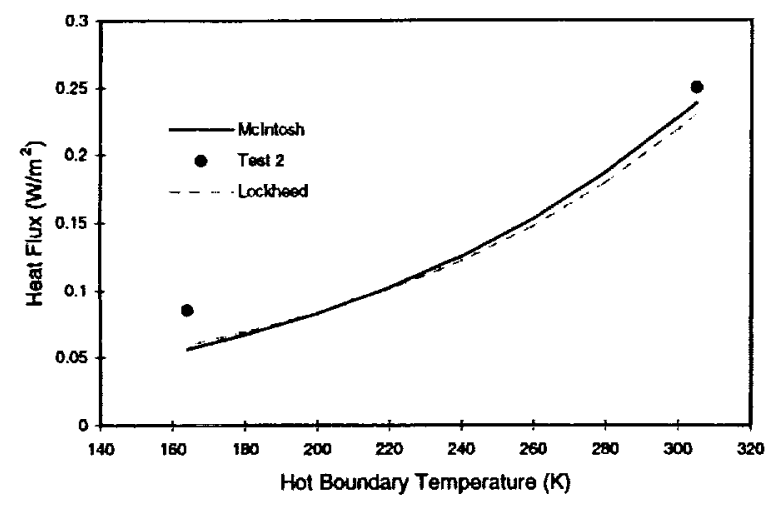

Figure 2. Heat Flux for 45 Layers MLI

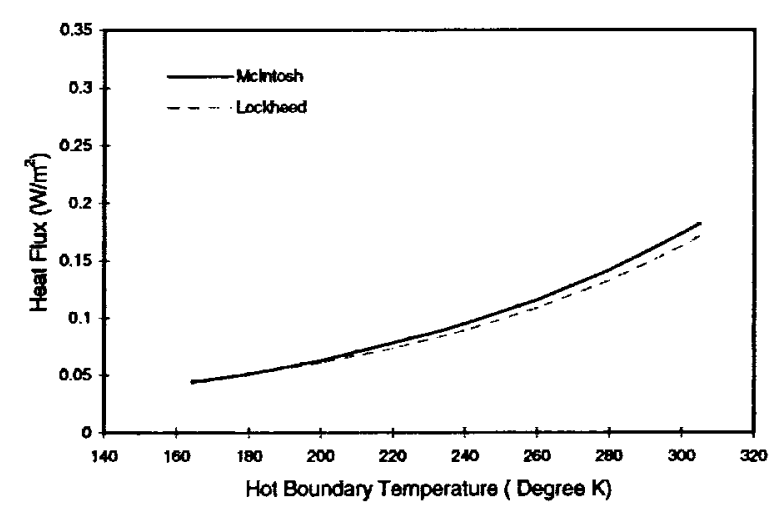

Figure 4. Heat Flux for 60 Layers MLI

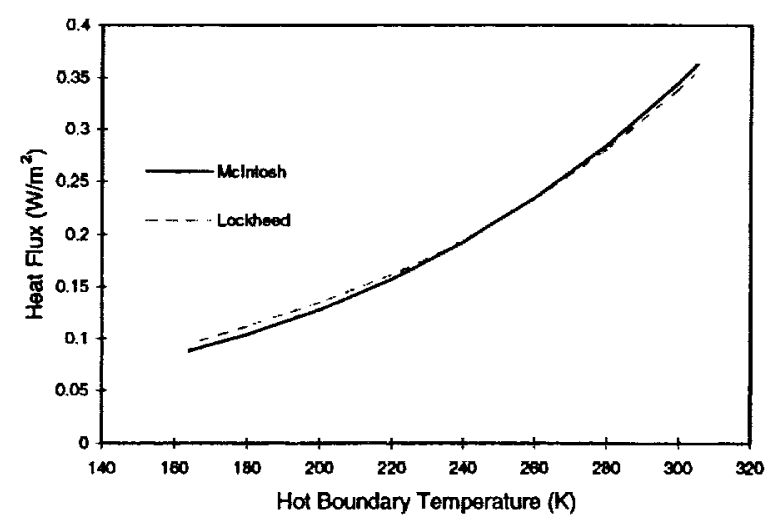

Figure 3. Heat Flux for 30 Layers MLI

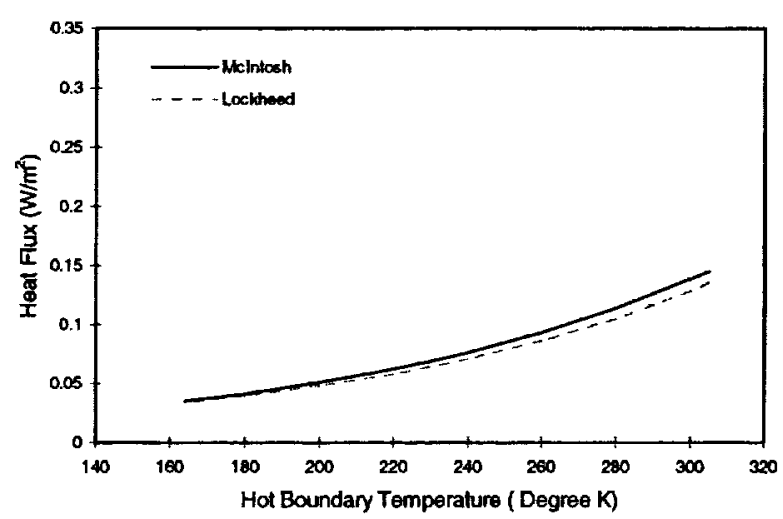

Figure 5. Heat Flux for 75 Layers MLI

\begin{tabular}{|c|c|c|c|}
\hline \multicolumn{4}{|c|}{ Upper Stage LH2 Tank MLI Application Examples } \\
\hline \multicolumn{1}{|c|}{ MLI System } & $\begin{array}{c}\text { Applied MLI } \\
\text { Weight } \\
(\mathrm{kg})\end{array}$ & $\begin{array}{c}45 \text { Day } \\
\text { Boiloff } \\
(\mathrm{kg})\end{array}$ & $\begin{array}{c}45 \text { day Boiloff } \\
(\%)\end{array}$ \\
\hline mil Aluminum Mylar layer & 57 & 159 & 4.6 \\
Variable Density MLI & 56 & 382 & 11.0 \\
Standard MLI & 100 & 159 & 4.6 \\
\hline
\end{tabular}

Table 1. Variable Density and Standard MLI Application Comparison. 